\title{
Spent coffee grounds for biodiesel production and other applications
}

\author{
Nídia S. Caetano · Vânia F. M. Silva \\ Ana C. Melo · Antó nio A. Martins \\ Teresa M. Mata
}

\begin{abstract}
This work evaluates the possibility of using spent coffee grounds (SCG) for biodiesel production and other applications. An experimental study was conducted with different solvents showing that lipid content up to 6 wt\% can be obtained from SCG. Results also show that besides biodiesel production, SCG can be used as fertilizer as it is rich in nitrogen, and as solid fuel with higher heating value (HHV) equivalent to some agriculture and wood residues. The extracted lipids were characterized for their properties of acid value, density at $15{ }^{\circ} \mathrm{C}$, viscosity at $40^{\circ} \mathrm{C}$, iodine number, and $\mathrm{HHV}$, which are negatively influenced by water content and solvents used in lipid extraction. Results suggest that for lipids with high free fatty acids (FFA), the best procedure for conversion to
\end{abstract}

biodiesel would be a two-step process of acid esterification followed by alkaline transesterification, instead of a sole step of direct transesterification with acid catalyst. Biodiesel was characterized for its properties of iodine number, acid value, and ester content. Although these quality parameters were not within the limits of NP EN 14214:2009 standard, SCG lipids can be used for biodiesel, blended with higher-quality vegetable oils before transesterification, or the biodiesel produced from SCG can be blended with higher-quality biodiesel or even with fossil diesel, in order to meet the standard requirements.

\section{Keywords}

Biodiesel · Fertilizer - Lipid extraction - Solid fuel · Spent coffee grounds

\section{Introduction}

Biodiesel is a renewable fuel that is being increasingly used in Europe, alternatively or in addition to fossil diesel, with the main goals of reducing the dependence on fossil fuels in the transportation sector, and increase fuel renewability with positive impacts in the environment (Mata et al. 2013). Its production involves a transesterification, a reversible reaction with three successive steps, where triglycerides are converted to diglycerides, diglycerides to monoglycerides, and monoglycerides to esters and glycerol. From this reaction, it results in three moles of fatty acid monoalkylester (biodiesel) and a mole of glycerol as a by-product. Strong alkali-catalysts are normally used in industrial practice, but other catalysts such as enzymes (Caetano et al. 2012a) are also possible, though they are still under development. The overall transesterification reaction of triglycerides is shown in Eq. 1. 


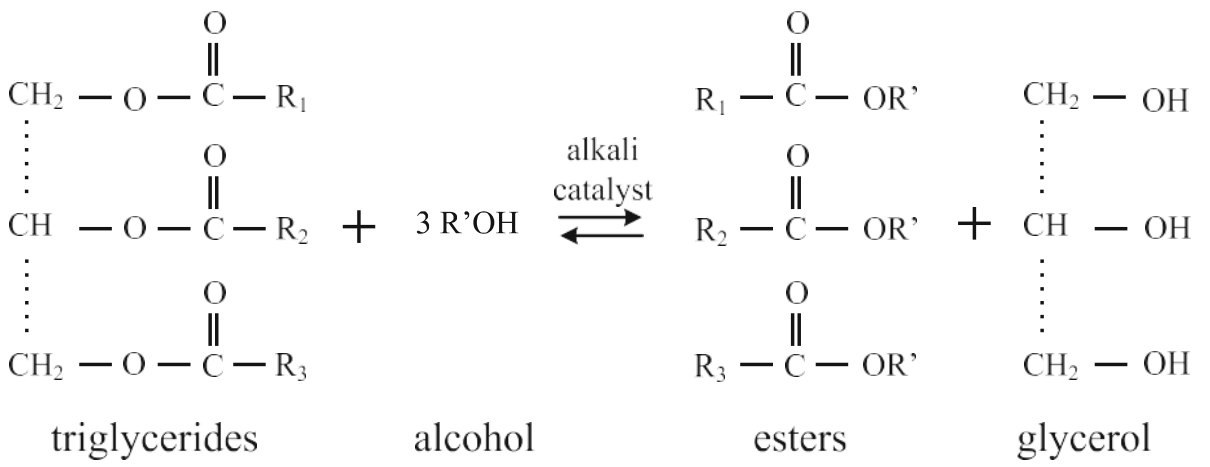

Because the transesterification reactions are reversible, an excess of a primary alcohol is required to shift the equilibrium to the product side and ensure full conversion of the triglycerides. Although several process variants exist or were proposed, most of the current production units use methanol in stoichiometric excess, normally the triglycerides/alcohol ratio is 1:6. Sodium hydroxide is normally used as catalyst, in a heated stirred tank reactor at around $60{ }^{\circ} \mathrm{C}$. A complete description of the process and variants is outside the scope of this article but can be found in the literature (Mata and Martins 2010).

Biodiesel feedstocks containing 5 to $30 \%$ acidity or even higher need to be first pre-treated by acid-catalyzed esterification, to reduce their free fatty acids (FFA) content, prior to transesterification. The esterification reaction is represented by Eq. 2 .

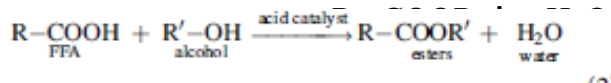

Excess methanol (20:1 ratio) is generally necessary to ensure full conversion of FFA.

Biodiesel demand is increasing significantly, as consumers are using even more environmentally friendly fuels, and as policy goals of national and international strategies need to be fulfilled. This situation represents a significant challenge as presently, the dominant biodiesel feedstocks are oleaginous crops, also used in human consumption (Mata et al. 2011). Their usage is being increasingly questioned, as they have some significant sustainability issues, such as diversion of arable land from food to biofuel, deforestation to gain more arable land, as well as some societal and/or economic constraints due to food price increases. Among the potential alternatives for biodiesel production, particular attention is being given to microalgae that have potentially high biomass and lipid productivities, can utilize different water sources such as an industrial wastewater (Mata et al. 2012), with minimal competition with conventional agriculture, and to residual materials with significant lipid content such as waste cooking oil, animal fats or grease (Mata et al. 2010), or even to other oil rich wastes such as the SCG.

In fact, coffee is currently known as one of the most widespread types of beverages consumed around the world, and one of the largest commodities, with a world production of around 8 million tons, most of it aimed for beverages (USDA 2013), with an increasing demand (Mussatto et al. 2011b). The coffee annual consumption in Portugal was around 43,000 tons in 2011, which was an already significant consumption (ChartsBin.com 2014) Hence, as a consequence of the coffee-drink making process there is a significant generation of residues (known as SCG) that need to be adequately managed. Currently, most of those residues end up in landfills; where together with other organic waste may be decomposed to methane and thus contribute to climatic change.

SCG is an organic residue that can be treated or valorized in a variety of ways, reducing its environmental impact. Many options can be considered to manage this waste material. A review of the various possibilities can be found in the work of Mussatto et al. (2011b). Besides dumping in landfills, which means that there will be almost no valorization, other options include: utilization in animal feeding (Givens and Barber 1986), production of organic compost or as fertilizer (Adi and Noor 2009), anaerobic digestion (Dinsdale et al. 1996), or even as solid fuel (Kondamudi et al. 2008). More recently other applications are being considered, including its use to remove heavy metals (Lavecchia et al. 2010), extraction of high-value compounds (Panusa et al. 2013), feedstock for activated carbon production (Kante et al. 2012), bioethanol production (Mussatto et al. 2012), among others.

Of interest to this article is the possibility of valorizing this residue for biodiesel production to be used as transportation fuel. The SCG lipid content can reach values of 18 to $20 \%$ in mass, with a lipid content profile suitable to be converted to biodiesel (Mussatto et al. 2011b). The potential biodiesel that can be processed from SCG is 
estimated to be around 1 billion liters per year (Kondamudi et al. 2008). Hence, there is interest in evaluating the potential of this waste material as an alternative feedstock for biodiesel production (Kwon et al. 2013). Although studies showed that biodiesel can be obtained from the SCG lipids (Vardon et al. 2013), there are still some unanswered questions to be addressed. In particular, it is still necessary to identify which are the best lipid extraction methodologies, in order to be cost effective and to convert efficiently lipids to biodiesel, and how to manage the residual SCG biomass remaining after the lipid extraction. Therefore, through several laboratorial experiments, this work aims to explore the production of biodiesel from SCG, analyzing the best solvent or mixture of solvents to perform the lipid extraction, and the possibility of using the extracted biomass for other purposes such as solid fuel or as fertilizer.

\section{Materials and methods}

\section{SCG characterization}

For this study, the SCG were collected from a local coffee shop, the type of places where coffee is mostly consumed in Portugal, and where SCG can be easily collected, as this residue is normally deposited in specific containers. First, the SCG obtained were characterized for their humidity, total carbon (TC), total nitrogen (TN), protein, ash, cellulose, and lignin content as described by Caetano et al. (2012b). The SCG were allowed to air dry for several days and then characterized to evaluate its moisture content by repeated cycles of oven (WTB Binder) drying at $105 \pm 5{ }^{\circ} \mathrm{C}$ followed by cooling in a desiccator and weighing until a constant weight. The TC was determined using a SHIMADZU, TOC-VCSN Analyzer. The TN was determined using a conventional Kjeldahl procedure (sample digestion with $\mathrm{H}_{2} \mathrm{SO}_{4}$ in a Raypa digestor, and distillation using a Raypa DNP1500 distiller, followed by titration). The protein content was estimated according to the procedure suggested by Alves et al. (2007), the ash content according to the Standard Methods 2540 E (APHA 1999), using a furnace (Vulcan A-550) at $550 \pm 5{ }^{\circ} \mathrm{C}$. The cellulose content was determined according to the procedures of the Portuguese standard NP-1005:1974, using a heating plate (SELECTA, Agimatic-E), a vacuum filtration apparatus and a vacuum pump (Neuberger), an analytical balance (Kern ALJ 220-4), a furnace (Vulcan A-550), and an oven (WTB Binder). The insoluble (or Klason) and soluble lignin content were determined according to the procedure of the standard TAPPI T222om-02, using a heating plate (SELECTA, Agimatic-E) and a UV-Vis spectrophotometer (Shimadzu, UV-1700 pharmaspec) to measure the absorbance of the filtered solution resulting from the previous procedure at a $205 \mathrm{~nm}$ wavelength. SCG energy content (or higher heating value, HHV) was determined using a Parr 6722 calorimeter, according to the ASTM D5865-10 standard.

Lipid extraction and recovery

Lipids from SCG were extracted using a pilot scale Soxhlet at constant ratio of $2.4 \mathrm{~kg} \mathrm{SCG} / 10 \mathrm{~L}$ solvent, using the following different solvents and their mixtures:

(A) Mixture of pure hexane (pa, $96 \%$, Carlo Erba) and isopropanol (pa, Carlo Erba) (50:50 vol/vol)

(B) Mixture of commercial hexane (Labsolve) and isopropanol $(50: 50 \mathrm{vol} / \mathrm{vol})$

(C) Mixture of recovered hexane and isopropanol

(D) Pure hexane (pa, $96 \%$, Carlo Erba) for extracting dry SCG

(E) Pure hexane (pa, $96 \%$, Carlo Erba) for extracting wet SCG

(F) Commercial hexane (Labsolve) for extracting wet SCG.

Therefore, about $2.4 \mathrm{~kg}$ of SCG was extracted with about $10 \mathrm{~L}$ of the selected solvent (or mixture of solvents), for several extraction cycles, until obtaining a constant refraction index of the solvent measured in three consecutive samples. To recover the extracted lipids and the solvents, a rotary evaporator (Rotavapor, Heidolph) and a vacuum pump (Neuberger) were used.

\section{Lipids characterization}

The recovered lipids were characterized for some important parameters to evaluate its quality. Thus, acid value was determined by volumetric titration, iodine number was determined by a titrimetric method using Wijs reactant, kinematic viscosity was determined at $40{ }^{\circ} \mathrm{C}$ using a Cannon-Fenske viscometer and a thermostatic water bath (Thermomix BM), density was determined at $15^{\circ} \mathrm{C}$ using a hydrometer method, and water content was determined by Karl Fischer coulometric titration (according to the standards specified in EN 14214:2009). Also, the higher heating value (HHV) was determined using an oxygen bomb calorimeter (Parr 6722), according to the procedure described in the ASTM D5865-10 standard.

\section{Biodiesel production}

Biodiesel was produced according to the following three methods: 
1. For the lipids extracted with pure hexane and isopropanol (50:50 vol/vol) (case B, described in Sect. 2.2), biodiesel was produced by transesterification. The transesterification reaction is performed by adding $40 \mathrm{wt} \%$ of methanol (Analytical Reagent Grade, Fisher Scientific) with previously dissolved $1.4 \mathrm{wt} \%$ of $\mathrm{NaOH}$ catalyst (Jose' M. Vaz Pereira), for $3 \mathrm{~h}$ at $60{ }^{\circ} \mathrm{C}$ and $80 \mathrm{rpm}$. Then, biodiesel is separated from the glycerol phase in a separatory funnel, washed with water acidified with a few drops of concentrated $\mathrm{H}_{3} \mathrm{PO}_{4}$, to neutralize the excess $\mathrm{NaOH}$, followed by washing with distilled water until neutral $\mathrm{pH}$. A further step of drying is carried out over the neutralized biodiesel by adding magnesium oxide $(\mathrm{MgO})$ and stirring the suspension for $15 \mathrm{~min}$, followed by vacuum filtration in cellulose membranes (Whatman, 4-7 1m) to remove the particles of $\mathrm{Mg}(\mathrm{OH})_{2}$ and $\mathrm{MgO}$ particles.

2. For the lipids extracted from dry SCG with pure hexane (case D, described in Sect. 2.2), it was firstly applied an acid-catalyzed esterification, consisting of a pre-treatment to reduce the acid value of oils in order to increase the reaction yield. Thus, several esterification steps were performed successively at $60{ }^{\circ} \mathrm{C}$ and $500 \mathrm{rpm}$ in an orbital acclimatized shaker (Ivymen, 200D N/S), controlling the esterification process every two hours by determining the acid value. At the end of each step the phases of methanol/ $\mathrm{H}_{2} \mathrm{O}$ were allowed to separate, and again about $1 \%(\mathrm{wt} / \mathrm{vol})$ of $\mathrm{H}_{2} \mathrm{SO}_{4}$ (96\%, Panreac) and $40 \mathrm{wt} \%$ of methanol (Analytical Reagent Grade, Fisher Scientific) were added to the reaction flask to perform another esterification step. When the acid value of the resulting product is lower than $3(\mathrm{mg} \mathrm{KOH}) /(\mathrm{g}$ oil $)$, the transesterification reaction is performed as described above in method 1 .

3. The lipids extracted using all solvents and methods (cases A to E, described in Sect. 2.2) were converted to biodiesel and then recovered following the Lepage and Roy (1984) method, with slight modifications as follows: The crude lipids (about $10 \mathrm{mg}$ ) are dissolved using $2 \mathrm{~mL}$ of a freshly prepared mixture of chloroform-methanol $(2: 1, \mathrm{v} / \mathrm{v})$ in a $10-\mathrm{mL}$ Pyrex tube with a Teflon-sealed screw cap previously weighted. For the lipids transesterification it is added $1 \mathrm{~mL}$ of methanol as reagent and $0.3 \mathrm{~mL}$ of sulfuric acid 95-97\% (Scharlau Chemie, reagent grade) as catalyst. After screwing the lid, the tube with the mixture is stirred vigorously for $5 \mathrm{~min}$ to start the reaction. The tube is placed in a digester (ECO 16 Thermoreactor Velp Scientifica) for the reaction to take place at $100{ }^{\circ} \mathrm{C}$ for $10 \mathrm{~min}$. After cooling down the tube to room temperature, $1 \mathrm{~mL}$ of distilled water is added to promote phase separation (two distinct phases are formed, the upper layer rich in water, methanol, glycerol, and sulfuric acid, and the lower layer rich in chloroform and esters). After separating and discarding the upper layer, again $1 \mathrm{~mL}$ of distilled water is added for a gentle water washing of the esters and chloroform layer (more dense than the water layer) followed by discard of the water rich upper layer (less dense). This step is repeated more than two times. The ester-rich layer is filtered using a disposable Nylon syringe filter (0.2 $1 \mathrm{~m}$ pore, and $13 \mathrm{~mm}$ diameter, Cronus, UK). To recover the esters, chloroform is allowed to evaporate to dryness at room temperature (at about $25{ }^{\circ} \mathrm{C}$ ) in a laboratorial hood.

\section{Biodiesel characterization}

The European standard EN 14214 (2009) specifies a large amount of parameters and corresponding procedures for biodiesel characterization. In this work, it was evaluated the visual appearance of biodiesel (color and physical state), acid and iodine values, water content, reaction yield, and methyl ester content (by EN 14103 standard). The ester content was determined by gas chromatography using a Dani GC 1000 DPC gas chromatograph (DANI Instruments S.P.A.) equipped with an AT-WAX (Heliflex capillary, Alltech) column $(30 \mathrm{~m}, 0.32 \mathrm{~mm}$ internal diameter, and $0.25-1 \mathrm{~m}$ film thickness). The injector temperature was set to $250{ }^{\circ} \mathrm{C}$, while the flame ionization detector (FID) temperature was set to $250{ }^{\circ} \mathrm{C}$ and the oven temperature to $195^{\circ} \mathrm{C}$. Helium at $1 \mathrm{~mL} / \mathrm{min}$ was used as the carrier gas. A $0.1-1 \mathrm{~L}$ sample was injected in a split mode, using a 1:80 split ratio.

Results and discussion

\section{SCG composition}

The SCG were characterized in this study, before and after lipid extraction. The obtained results, as well as some reference values from literature used for comparison, are shown in Table 1.

Extraction of lipids from SCG contributes also to its water removal as demonstrated by the huge drop in moisture content (values before and after extraction in Table 1).

The HHV of the extracted SCG is slightly lower than that of the raw SCG. The amounts of water and lipids in the SCG are lower, which has opposite effect on the energy content of the spent coffee grounds, and similar to other agriculture residues such as straw $(18.5 \mathrm{MJ} / \mathrm{kg})$ and to some types of wood residues, such as eucalyptus (19.2-19.4 MJ/kg) (Sousa 2009), allowing it to be used as solid fuel.

Upon extraction, the $\mathrm{C} / \mathrm{N}$ ratio increased from 30 to 35 , but if only cellulose and not lignin is considered, the $\mathrm{C} / \mathrm{N}$ 
Table 1 Characterization of SCG

\begin{tabular}{llll}
\hline Parameter & $\begin{array}{l}\text { Before } \\
\text { extraction }\end{array}$ & $\begin{array}{l}\text { After } \\
\text { extraction }\end{array}$ & $\begin{array}{l}\text { Reference } \\
\text { value }\end{array}$ \\
\hline $\begin{array}{l}\text { Higher heating value, } \\
\quad \text { HHV (MJ/kg) }\end{array}$ & 19.3 & 19.0 & $21.8-26.9^{\mathrm{a}}$ \\
Moisture (\%) & 65.7 & 9.4 & $1.18-5.54^{\mathrm{b}}$ \\
Total carbon $(\%, \mathrm{dwt})$ & 67.3 & 69.5 & $47.8-58.9^{\mathrm{a}, \mathrm{c}}$ \\
Total nitrogen $(\%, \mathrm{dwt})$ & 2.2 & 2.0 & $1.9-2.3^{\mathrm{c}, \mathrm{d}}$ \\
Protein (g protein/100 g) & 13.7 & 12.3 & $6.7-13.6^{\mathrm{b}, \mathrm{e}}$ \\
Ash $(\%$, dwt) & 2.2 & 1.65 & $0.43-1.6^{\mathrm{b}, \mathrm{e}}$ \\
Cellulose $(\%, \mathrm{dwt})$ & 13.8 & 15.3 & $8.6^{(\mathrm{f})}$ \\
Klason lignin $(\%, \mathrm{dwt})$ & 31.9 & 30.9 & - \\
Soluble lignin $(\%, \mathrm{dwt})$ & 1.7 & 1.6 & - \\
Total lignin $(\%, \mathrm{dwt})$ & 33.6 & 32.5 & - \\
\hline
\end{tabular}

a Bizzo (2003)

b Lago et al. (2001)

c Melo et al. (2007)

d Nogueira and Costa (1999)

e Mussatto et al. (2011a)

f Mussatto et al. (2011b)

ratio is about 8 , meaning that SCG can be used as fertilizer rich in nitrogen. Also, the extraction procedure contributes to lignin solubilization, possibly due to the effect of the solvent that causes extreme swelling of the lignin molecules and finally breaks down the polymer chains. Despite this, the main differences from the experimental results to those found in the literature lie in the TC and cellulose content (respectively, higher and lower in this work) and, consequently, on the energy content of the SCG (that is lower in this work). This may be due to the differences in the original composition of the SCG used in this study and in the other studies.

The high cellulose content of the extracted SCG means that it can also be used for bioethanol production.

Effect of moisture on lipid extraction and quality

In order to identify the influence of the presence of moisture and of the ultrasounds use in the lipid extraction from SCG, some preliminary experiments were run using only hexane, either with dry or wet SCG and with or without sonication, being the total extraction time $25 \mathrm{~h}$. The corresponding results are shown in Table 2 .

Results show that the use of ultrasounds did not improve lipid extraction but the presence of moisture significantly hindered it. Therefore, this work proceeded with the lipid extraction from dried SCG. As mentioned above, the lipid extraction was performed using a pilot scale Soxhlet, at constant ratio of $2.4 \mathrm{~kg} \mathrm{SCG} / 10 \mathrm{~L}$ solvent, using different solvents and their mixtures (as described in Sect. 2.2). Results of the extraction process under these conditions and solvents are shown in Table 3 .

In which concerns the water content, it is significantly higher (of $0.853 \%$ ) in the lipids extracted with the recovered hexane/isopropanol mixture $(\mathrm{C}$, as described in Sect. 2.2), whereas it is lower in the lipids extracted with the mixture of pure solvents (A). The same trend is observed when commercial $(F)$ versus pure (D) hexane is used. This may be due to the presence of larger amounts of water in the lower-purity solvents. The study of Caetano
Table 2 Effect of sonication and water content of SCG in lipid extraction

\begin{tabular}{llll}
\hline Parameter & Sonication & Contact time & $\begin{array}{l}\text { Lipid } \\
\text { content } \\
\text { (wt\%) }\end{array}$ \\
\hline Dry SCG & Yes & 1 min manual ? 10 min ultra sounds & 5.3 \\
& No & 1 min manual & 6.0 \\
Wet SCG $(65.7 \%$ moisture $)$ & Yes & 1 min manual ? 10 min ultra sounds & 1.8 \\
& No & 1 min manual & 2.9 \\
\hline
\end{tabular}

Table 3 Characterization of lipids extracted from SCG using different solvents

\begin{tabular}{|c|c|c|c|c|c|c|}
\hline \multirow[t]{2}{*}{ Parameter } & \multicolumn{6}{|c|}{ Extraction solvent(s) } \\
\hline & A & $\mathrm{B}$ & $\mathrm{C}$ & $\mathrm{D}$ & $\mathrm{E}$ & $\mathrm{F}$ \\
\hline Color & Dark brown & Dark brown & Dark brown & Dark brown & Dark brown & Dark brown \\
\hline Moisture (\%) & 0.092 & 0.118 & 0.853 & 0.114 & 0.119 & 0.132 \\
\hline HHV (MJ/kg) & 39.4 & 35.4 & 18.4 & 40.8 & 38.9 & 36.1 \\
\hline Density at $15^{\circ} \mathrm{C}\left(\mathrm{kg} / \mathrm{m}^{3}\right)$ & 927 & 934 & na & 912 & 929 & 942 \\
\hline Viscosity $40{ }^{\circ} \mathrm{C}\left(\mathrm{mm}^{2} / \mathrm{s}\right)$ & 33.0 & 43.9 & na & 14.9 & 39.8 & 40.6 \\
\hline Acid value (mg KOH/g SCG) & 3.9 & 5.6 & 21.8 & 9.9 & 9.4 & 12.5 \\
\hline Iodine value ( $\left.\mathrm{g} \mathrm{I}_{2} / 100 \mathrm{~g} \mathrm{SCG}\right)$ & 61.5 & 70.5 & 49.0 & 47.6 & 67.9 & 51.4 \\
\hline
\end{tabular}


Table 4 Methyl ester content of biodiesel from SCG

\begin{tabular}{|c|c|c|c|}
\hline $\begin{array}{l}\text { Extraction } \\
\text { solvent(s) }\end{array}$ & $\begin{array}{l}\text { Production } \\
\text { method }\end{array}$ & Experimental reaction conditions & $\begin{array}{l}\text { Ester } \\
\text { content } \\
(\%)\end{array}$ \\
\hline A & 3 & \multirow{5}{*}{$\begin{array}{l}10 \mathrm{mg} \text { lipids; } 2 \mathrm{~mL} \text { chloroform } / \text { methanol }(2: 1 \mathrm{vol} / \mathrm{vol}) ; 1 \mathrm{~mL} \\
\text { chloroform nonadecanoic acid standard; } 1 \mathrm{~mL} \text { methanol; } 300 \mathrm{1L} \\
\mathrm{H}_{2} \mathrm{SO}_{4} \text {; mixing } 5 \mathrm{~min} \text {; reaction at } 100{ }^{\circ} \mathrm{C} \text { for } 10 \mathrm{~min}\end{array}$} & 62.2 \\
\hline B & 3 & & 70.9 \\
\hline $\mathrm{C}$ & 3 & & 61.5 \\
\hline D & 3 & & 47.4 \\
\hline E & 3 & & 63.4 \\
\hline B & 1 & 40 wt $\%$ Methanol; 1.4 wt $\% \mathrm{NaOH} ; 60^{\circ} \mathrm{C} ; 3 \mathrm{~h} ; 80 \mathrm{rpm}$ & 86.0 \\
\hline D & 2 & Esterification; $40 \%$ Methanol; $1 \mathrm{wt} \% \mathrm{NaOH} ; 60^{\circ} \mathrm{C} ; 2 \mathrm{~h}$; & 63.0 \\
\hline D & 2 & Esterification; $60 \mathrm{wt} \%$ Methanol; $1 \% \mathrm{NaOH} ; 60^{\circ} \mathrm{C} ; 2 \mathrm{~h}$; & 65.0 \\
\hline D & 2 & Esterification; $80 \mathrm{wt} \%$ Methanol; $1 \% \mathrm{NaOH} ; 60{ }^{\circ} \mathrm{C} ; 2 \mathrm{~h}$; & 54.2 \\
\hline
\end{tabular}

et al. (2012b) also revealed a very high water content of $2,004 \mathrm{ppm}$ (corresponding to about $0.2 \%$ of moisture) in the SCG oil after the extraction using a mixture of hexane and isopropanol 50:50 (vol/vol) as extracting solvents.

Regarding the HHV, it is higher $(40.8 \mathrm{MJ} / \mathrm{kg}$ ) for the lipids extracted from dry SCG with pure hexane (D), and the lowest value $(18.4 \mathrm{MJ} / \mathrm{kg})$ was obtained for the lipids extracted with the recovered mixture of solvents (C). This may also be due to the higher water content of the later lipids. The density and the viscosity of lipids extracted from dry SCG with hexane were the lowest, but for the same solvent, when wet SCG was used, the highest values were observed.

The acid value of lipids extracted with the lowest-purity solvents was significantly higher than the one of lipids extracted with the most pure solvents or from wet SCG. This may be due to the presence of impurities in the solvents that are of acid nature. The acidity of the extracted lipids is too high in order to be directly transesterified (especially the samples of lipids extracted with the recovered mixture of solvents and with hexane), requiring a previous esterification pretreatment step. The study of Vardon et al. (2013) also revealed a relatively high acid value $(11.27 \mathrm{mg} \mathrm{KOH} / \mathrm{g})$ in spent coffee lipids.

Regarding the iodine value, the highest value was the one obtained for the lipids extracted with the mixture of commercial solvents (B), being the lowest value obtained using pure hexane for extracting dry SCG (D) followed by the recovered mixture of solvents (C), so it seems that the quality of the extracted lipids is significantly affected by the quality of the solvents and by the presence of water in the SCG. Also iodine value is very low, meaning that the coffee oil is very saturated (with few double bond fatty acids).

\section{Biodiesel production and properties}

As stated before, biodiesel was produced using the lipids extracted with different solvents (as described in Sect. 2.2)
Table 5 Biodiesel characterization

\begin{tabular}{lll}
\hline Parameter & Biodiesel & EN 14214: \\
& & 2009 limits \\
\hline Color & Dark brown & - \\
Appearance & Liquid & - \\
Reaction yield (wt\%) & 37.3 & - \\
Water content (ppm) & 2,708 & $\backslash 500$ \\
Iodine value $\left(\mathrm{g} \mathrm{I}_{2} / 100 \mathrm{~g}\right.$ sample) & 70 & $\backslash 120$ \\
Acid value (mg KOH/g sample) & 1.85 & $\backslash 0.5$ \\
Methyl ester content $(\mathrm{wt} \%)$ & 86.0 & $\mathbf{[ 9 6 . 5}$ \\
\hline
\end{tabular}

and according to the experimental procedures (described in Sect. 2.4). These and the corresponding results are shown in Table 4.

Results show that the ester content of biodiesel obtained from SCG vary between 47.4 and $86.0 \%$ depending on the extracting solvents and reaction conditions used for, respectively, obtaining the lipids and converting them to biodiesel. This is in agreement with the results of Oliveira et al. (2008) that obtained an ester yield between 35.0 and $70.1 \%$. According to the results, the lipids resulting from the dry SCG extraction with pure hexane (D) yielded the lowest methyl ester content, when an acid esterification was performed over the lipids (methods 2 and 3), whereas the highest methyl ester content was obtained for the lipids extracted with the mixture of commercial solvents (B). This may be due to the removal of the glycerol formed during the reaction, due to the simultaneous presence of isopropanol. Nevertheless, the biodiesel produced from the lipids extracted with the mixture of commercial solvents

(B) under the conventional alkaline transesterification procedure (method 1) was the one with the highest methyl ester content of $86 \%$, still substantially below the limiting value of $96.5 \%$ imposed by the EN 14214 (2009) standard. This may be due to the presence of FFA in the lipids that may have been saponified and thus, reduced the methyl ester yield. This problem could be partially reduced by 
performing an esterification of the lipids previously to the transesterification reaction, as it was done in the samples of lipids extracted from dry SCG with pure hexane. In fact, this procedure allowed for much higher methyl ester content $(65 \%)$ when compared to the direct transesterification procedure $(47.3 \%)$, although it is not possible to extrapolate the results, but is in good agreement to the results by Al-Hamamre et al. (2012). But biodiesel quality cannot be evaluated only by the methyl ester content. Therefore, for the biodiesel with the highest methyl ester content a more complete characterization was done. The results are shown in Table 5.

In spite of the acid value reduction, biodiesel still does not comply with the EN 14214 (2009) standard specifications. In particular, the water content may be substantially reduced by improving the drying procedure, and the acid value may be reduced either by increasing the lipids conversion, or by improving the neutralization procedure. The low reaction yield (37.3 wt $\%$ ) may be due to the high water content in the lipids and to the relatively high FFA content of lipids, which react with the catalyst and form soap that hinders the reaction.

\section{Conclusions}

This work evaluated SCG as feedstock for biodiesel production and other possibilities. The best result concerning lipid extraction (lipid content of $6 \mathrm{wt} \%$ ) was obtained using pure hexane and a mixture of pure hexane and isopropanol in the ratio of 50:50 ( $\mathrm{vol} / \mathrm{vol})$. The lipid content is higher (about double) when dry SCG is used instead of wet SCG (with a moisture content of about $66 \%$, vol/wt). The use of ultrasounds had no significant effect on the amount of extracted lipids. The carbon/ nitrogen ratio $(\mathrm{C} / \mathrm{N} \& 8)$ of SCG allows it to be used as $\mathrm{N}$ source, and its HHV $(19.0 \mathrm{MJ} / \mathrm{kg})$ is similar to that of other agriculture and wood residues, allowing it to be used as solid fuel. Regarding the lipids characterization, several parameters were negatively influenced by the water content and solvents used in the extraction process. Due to the relatively high FFA content, the lipids conversion to biodiesel was done in two steps of FFA esterification, followed by transesterification of triglycerides. This method showed a higher methyl ester content than the sole step of direct transesterification with $\mathrm{H} \mathrm{S}_{2} \mathrm{O}_{4}$.

Biodiesel characterization revealed an iodine value of about $70.0 \mathrm{~g} \mathrm{I}_{2} / 100 \mathrm{~g}$ biodiesel, an acid value of about $1.8 \mathrm{mg} \mathrm{KOH} / \mathrm{g}$ biodiesel and ester content of about $86 \%$. Although these values are not within the limits of EN 14214:2009 standard, there is the potential for using SCG for biodiesel production.

\section{References}

Adi AJ, Noor ZM (2009) Waste recycling: utilization of coffee grounds and kitchen waste vermicomposting. Bioresour Technol 100:1027-1030

Al-Hamamre Z, Foerster S, Hartmann F, Kroger M, Kaltschmitt M (2012) Oil extracted from spent coffee grounds as a renewable source for fatty acid methyl ester manufacturing. Fuel 96:70-76

Alves B, Nascimento E, Aquino F, Chang R, Morais S (2007) Chemical composition of roasted coffee from the Cerrado and South Minas Gerais [Composição química de cafés torrados do Cerrado e do Sul de Minas Gerais] (in Portuguese). Ciência \& Engenharia 16(1/2):9-15

APHA (1999) Standard methods for the examination of water and wastewater, 20th edn. American Public Health Association, Washington, DC

Bizzo W (2003) Generation, distribution and use of steam. Apostila de Curso. UNICAMP, Campinas (in Portuguese)

Caetano NS, Teixeira JIM, Mata TM (2012a) Enzymatic catalysis of vegetable oil with ethanol in the presence of co-solvents. Chem Eng Trans 26:81-86. doi:10.3303/CET1226014

Caetano NS, Silva VFM, Mata TM (2012b) Valorization of coffee grounds for biodiesel production. Chem Eng Trans 26:267-272. doi:10.3303/CET1226045

ChartsBin.com (2014) Current Worldwide Annual Coffee Consumption per capita. http://chartsbin.com/view/581. Accessed 22 Mar 2014

Dinsdale RM, Hwakes FR, Hwaked DL (1996) The mesophilic and thermophikic anaerobic digestion of coffee waste containing coffee grounds. Water Res 30:371-377

EN 14214 (2009) Automotive fuels: fatty acid methyl esters (FAME) for diesel engines - requirements and test methods. European Committee for Standardization

Givens D, Barber W (1986) In vivo evaluation of spent coffee grounds as a ruminant feeds. Agric Wastes 18:69-72

Kante K, Delgado CN, Mendes JR, Bandosz TJ (2012) Spent coffeebased activated carbon: specific surface features and their importance for $\mathrm{H}_{2} \mathrm{~S}$ separation process. J Hazard Mater 201202:141-147

Kondamudi N, Mohapatra SK, Misra M (2008) Spent coffee grounds as a versatile source of green energy. J Agric Food Chem 56:11757-11760

Kwon EE, Yi H, Jeon YJ (2013) Sequential co-production of biodiesel and bioethanol with spent coffee grounds. Bioresour Technol 136:475-480

Lago R, Antoniassi R, Freitas S (2001) Proximate composition and of amino acids in green coffee, roasted coffee and soluble coffee grounds. Embrapa-Agroindústria de Alimentos (in Portuguese), II Simpósio de pesquisa dos Cafés do Brasil, pp 1473-1478

Lavecchia R, Pugliese A, Zuorro A (2010) Removal of lead from aqueous solutions by spent tea leaves. Chem Eng Trans 19:7378. doi:10.3303/CET1019013

Lepage G, Roy CC (1984) Improved recovery of fatty acid through direct transesterification without prior extraction or purification. J Lipid Res 25:1391-1396

Mata TM, Martins AA (2010) Biodiesel Production Processes. In: Delgado JMPQ (ed) Current trends in chemical engineering. Studium Press LLC, Houston, pp 313-343

Mata TM, Cardoso N, Ornelas M, Neves S, Caetano NS (2010) Sustainable production of biodiesel from tallow, lard and poultry and its quality evaluation. Chem Eng Trans 19:13-18. doi:10. 3303/CET1019003

Mata TM, Martins AA, Sikdar S, Costa CAV (2011) Sustainability considerations of biodiesel based on supply chain analysis. Clean Technol Environ Policy 13(5):655-671 
Mata TM, Melo AC, Simões M, Caetano NS (2012) Parametric study of a brewery effluent treatment by microalgae Scenedesmus obliquus. Bioresour Technol 107:151-158

Mata TM, Martins AA, Sikdar S, Costa CAV, Caetano NS (2013)

Sustainability analysis of biofuel processes through the supply chain using indicators. Sustain Energy Technol Assess 3:53-60 Melo G,

Melo V, Melo W (2007) Composting. Faculdade de Ciências Agrárias e Veterinárias, Jaboticabal, p 10 in Portuguese

Mussatto S, Carneiro L, Silva J, Roberto I, Teixeira J (2011a) A study on chemical constituents and sugars extraction from spent coffee grounds. Carbohydr Polym 83:368-374

Mussatto S, Machado E, Martins S, Teixeira J (2011b) Production, composition and application of coffee and its industrial residues. Food and Bioprocess Technol. 4(5):661-672

Mussatto S, Machado EMS, Carneiro LM, Teixeira JA (2012) Sugars metabolism and ethanol production from different yeast strains from coffee industry wastes hydrolysates. Appl Energy 92: 763768
Nogueira A, Costa D (1999) Temperature range for composting solid organic waste. Universidade Federal do Esp irito Santo, Brasil, p 8 (in Portuguese)

Oliveira LS, Franca AS, Camargos RRS, Ferraz VP (2008) Coffee oil as a potential feedstock for biodiesel production. Bioresour Tecnhol 99:3244-3250

Panusa A, Zuoro A, Lavecchia E, Marrosu G, Petrucci R (2013) Recovery of natural antioxidants from spent coffee grounds. J Agric Food Chem 61:4162-4168

Sousa C (2009) Energy recovery from industrial textiles and polymeric wastes. MSc thesis, Universidade do Minho, $130 \mathrm{pp}$ (in Portuguese)

USDA (2013) Coffee: world markets and trade. United States Department of Agriculture, Washington, DC

Vardon DR, Moser BR, Zheng W, Witkin K, Evangelista RL, Strathmann TJ, Rajagopalan K, Sharma BK (2013) Complete utilization of spent coffee grounds to produce biodiesel, bio-oil, and biochar. ACS Sustain Chem Eng 1:1286-1294 